Boletín de la Sociedad Geológica Mexicana

VOLUMEN 59, NÚM. 2, 2007, P. 147-162

\title{
Estudio geológico para entender los procesos de remoción en masa en la región de Zacapoaxtla, Puebla, México
}

\author{
Víctor Manuel Hernández-Madrigal1-2, Víctor Hugo Garduño-Monroy² e \\ Irasema Alcántara-Ayala ${ }^{1}$ \\ ${ }^{1}$ Unidad Académica de Geografía, Instituto de Geografía, Universidad Nacional Autónoma de México, \\ Antigua Carretera a Patzcuaro N 8701, Ex-Hda. San José de la Huerta, C.P. 58089. A.P. 3-72 (Xangari). Morelia, Mich., México. \\ ${ }^{2}$ Instituto de Investigaciones Metalúrgicas, Universidad Michoacana de San Nicolás de Hidalgo, \\ Edificio "U”, Ciudad Universitaria, Morelia, Mich., México. \\ vitorio_manuel@yahoo.it
}

\section{Resumen}

La región de Zacapoaxtla integrada por las Sierras Cinco de Mayo, Las Lomas, Atacpan, Tlatlauquitepec, Apulco y la Altiplanicie Zacapoaxtla, constituye una zona de transición geológica entre la Sierra Madre Oriental y el Cinturón Volcánico Transmexicano. La Sierra Madre Oriental se identifica en la región con afloramientos de rocas que van del Jurásico Temprano al Cretácico Tardío-Terciario, de facies que van de continentales (Fm. Cahuasas) a mixtas y marinas (Fm Molango); además de cuerpos intrusivos y sus respectivos metamorfismos de contacto. La actividad del Cinturón Volcánico Transmexicano se manifiesta en esta región, con un vulcanismo monogenético aislado y las formaciones Teziutlán, Apaxtepec e ignimbrita Xáltipan, esta última caracterizada geoquímicamente y dándole una extensión más importante. Con base en el análisis de la deformación de la Sierra Madre Oriental, distribución espacial de litologías e inestabilidad de laderas en el área de estudio, encontramos en este trabajo tres factores determinantes en los procesos de remoción en masa para la región de Zacapoaxtla: la geometría de la deformación en las unidades de la Sierra Madre Oriental teniéndose que para los estilos de rampas y cabalgaduras, los deslizamientos traslacionales se presentan en las rampas y las deformaciones gravitacionales profundas de ladera en los frentes de las cabalgaduras; propiedades mecánicas de los materiales blandos (arcillas y limos); y condiciones hidráulicas, mecánicas y geométricas en los depósitos de la ignimbrita Xáltipan no soldada.

Palabras clave: Región de Zacapoaxtla, Sierra Madre Oriental, Fm. Apaxtepec, ignimbrita Xáltipan, procesos de remoción en masa.

\begin{abstract}
The Zacapoaxtla region comprises the ridges Sierra Cinco de Mayo, Las Lomas, Atacpan, Tlatlauquitepec, Apulco and Zacapoaxtla plateau. It is a geologic transitional zone between the Sierra Madre Oriental and the Trans-Mexican Volcanic Belt. The Sierra Madre Oriental is characterized by a series of outcrops dated from the Lower Jurassic to the Late Cretaceous-Tertiary (Cahuasas, Molango and Valles petrotectonic units); as well as by intrusive bodies associated to contact metamorphism. The activity of the Trans-Mexican Volcanic Belt is expressed in this region by the Teziutlan, Apaxtepec geologic formations and by the emplacement of the Xáltipan ignimbrite, the latest identified by geochemical analyses and field mapping.

With base in the analysis of the deformation of the Sierra Madre Oriental, spatial distribution of lithlogies and landslides types on the study area, we found in this work three mains factors that explain the landslides for Zacapoaxtla area: the geometric deformation of the Sierra Madre Oriental being had that for the styles Ramps and Flats, the translational slides are presented in the ramps and gravitational deep deformations in the advance front; mechanical properties of the soft materials (clay and silt); and hydraulic, mechanical and geometric conditions of not welded Xáltipan ignimbrite.
\end{abstract}

Key words: Zacapoaxtla region, Sierra Madre Oriental, Apaxtepec geologic formation, Xáltipan ignimbrite, mass movement processes. 


\section{Generalidades}

\subsection{Introducción}

Situada en el centro de la Sierra Norte de Puebla, la Región de Zacapoaxtla (RdZ) aloja conjuntos de montañas de rocas sedimentarias plegadas e intrusionadas, que definen un relieve accidentado compuesto por escarpes, laderas y profundos barrancos, que han sido ocupados en los últimos cientos de años por depósitos piroclásticos provenientes del Centro Volcánico Los Humeros (CVLH). Estos depósitos piroclásticos forman altiplanicies sobre las cuales se han desarrollado poblaciones, algunas de origen prehispánico como la ciudad de Zacapoaxtla, localizada al centro de la región y fundada 200 años antes de la conquista por un grupo de tribus náhuatls o mexicas que la conocían con el nombre de "Zacaponloyan", que significa "lugar donde se cuenta el zacate".

A finales de 1999, durante los meses de septiembre y octubre, las depresiones tropicales 11 a 14 provocaron en la Sierra Norte de Puebla volúmenes excepcionales de precipitación que detonaron importantes inestabilidades de laderas (Lugo-Hubp, et al., 2001). En la RdZ, un deslizamiento de detritos y lodos, localizado $300 \mathrm{~m}$ al sur del Centro de Salud de Zacapoaxtla, sepultó varias viviendas y dejó seis personas desaparecidas (HernándezMadrigal, 2005). En el resto de la región, los procesos gravitativos inhabilitaron vías de comunicación terrestre y provocaron hundimientos y sepultamiento de viviendas, pérdida de suelo de cultivo y cobertura forestal, entre otros daños.

Diferentes exploraciones geológicas sobre el sur de la Sierra Madre Oriental y del Centro Volcánico los Humeros, constituyen fuentes aisladas de información somera y limitada que dificultan la interpretación geológica de la RdZ. Por tal motivo, en este trabajo se presenta primero una recopilación de información geológica de la región, representando tanto unidades del Mesozoico como aquellas volcánicas del Cenozoico, para llegar a la presentación del mapa geológico de la región de Zacapoaxtla. De este mapa destacan la Fm. Apaxtepec (Hernández-Madrigal, 2005), compuesta por un volcanismo monogenético; y depósitos piroclásticos que con base en datos geoquímicos se asocian a la ignimbrita Xáltipan, modificando con ello la distribución espacial de la ignimbrita Xáltipan reportada en la bibliografía. Finalmente se discute la relación entre procesos de remoción en masa y geometría de la deformación de la Sierra Madre Oriental.

Después de la crisis de 1999, en la RdZ como en el resto de la Sierra Norte de Puebla, se ve la necesidad urgente de iniciar trabajos especializados en el estudio de inestabilidad de laderas. La primera observación fue la de encontrar una cartografía geológica y geomorfológica adecuada, razón por la cual se preparó el presente trabajo.

Es importante señalar que existen pocos trabajos publicados en revistas especializadas sobre la zona, siendo los mas importantes: Ferriz, 1982, 1985; Verma y López, 1982; De la Cruz-Martínez, 1983; Ferríz y Mahood, 1984; Campa, 1985; Campos-Enríquez y Garduño-Monroy, 1987; Lugo-Hubp. 1999; Lugo-Hubp, et al, 2001, 2005; y Ángeles y Sánchez, 2002. Sin embargo son muchos los estudios realizados en ella por parte de PEMEX, por lo que consideramos muy importante que dichos estudios sean conocidos por la comunidad científica a fin de que puedan ser utilizados en buena forma.

\subsection{Localización}

La RdZ conocida como la Suiza poblana por sus amplios prados verdes y zonas arboladas, junto con las serranías de Tlatlauquitepec, Tetela, Chignahuapan, Zacatlán y Huachinango, integran la Sierra Norte de Puebla, localizándose $100 \mathrm{~km}$ al NE de la ciudad capital del estado de Puebla (Figura 1a). Sus coordenadas geográficas máximas son los paralelos $19^{\circ} 46^{\prime}$ y $19^{\circ} 59^{\prime}$ norte, y los meridianos $97^{\circ} 31^{\prime}$ y 97³9' oeste. El área de estudio limita al N, S, E, y O con las ciudades Nauzontla, Zaragoza, Tlatlauquitepec y Cinco de Mayo, respectivamente (Figura 1b). Con una extensión de $225.8 \mathrm{~km} 2$, la RdZ agrupa a más de 100 poblaciones de las cuales la ciudad de Zacapoaxtla destaca por su carácter histórico y comercial.

\subsection{Antecedentes}

Los estudios geológicos en la $\mathrm{RdZ}$ pueden ser divididos en dos, aquellos enfocados a la exploración de hidrocarburos en su mayoría no publicados, y los trabajos del Cinturón Volcánico Trasmexicano (CVTM).

El estudio de la geología de la $\mathrm{RdZ}$ se inicia con los trabajos de exploración para la producción de hidrocarburos, realizados por Petróleos Mexicanos (PEMEX), a partir de 1970 y hasta inicios de 1980, enfocando su atención en las unidades de la Sierra Madre Oriental (SMO) consideran dos aspectos relevantes, como rocas generadoras a las unidades del Jurásico y como rocas almacenadoras a las rocas cretácicas y terciarias. Los trabajos exploratorios de PEMEX agrupan a las litologías volcánicas del Cenozoico como una sola unidad. Un trabajo representativo de esta etapa, corresponde al desarrollo del Prospecto Huachinango, realizado por Morales y Garduño-Monroy (1984). Mediante una serie de columnas estratigráficas levantadas en campo, estos autores describen los diferentes Conjuntos Petrotectónicos que conforman el extremo sur del Terreno SMO.

A partir de 1980, con los estudio de Verma y López (1982), De la Cruz-Martínez (1983), Ferriz y Mahood (1984), Ferríz (1985), Campos-Enríquez y GarduñoMonroy (1987), Carrasco (1997) y Martínez-Serrano (2000), el estudio geológico de la zona cambia radicalmente al centrarse ahora en la evolución del CVLH, abordando el estudio de las unidades litológicas volcánicas y fuentes 


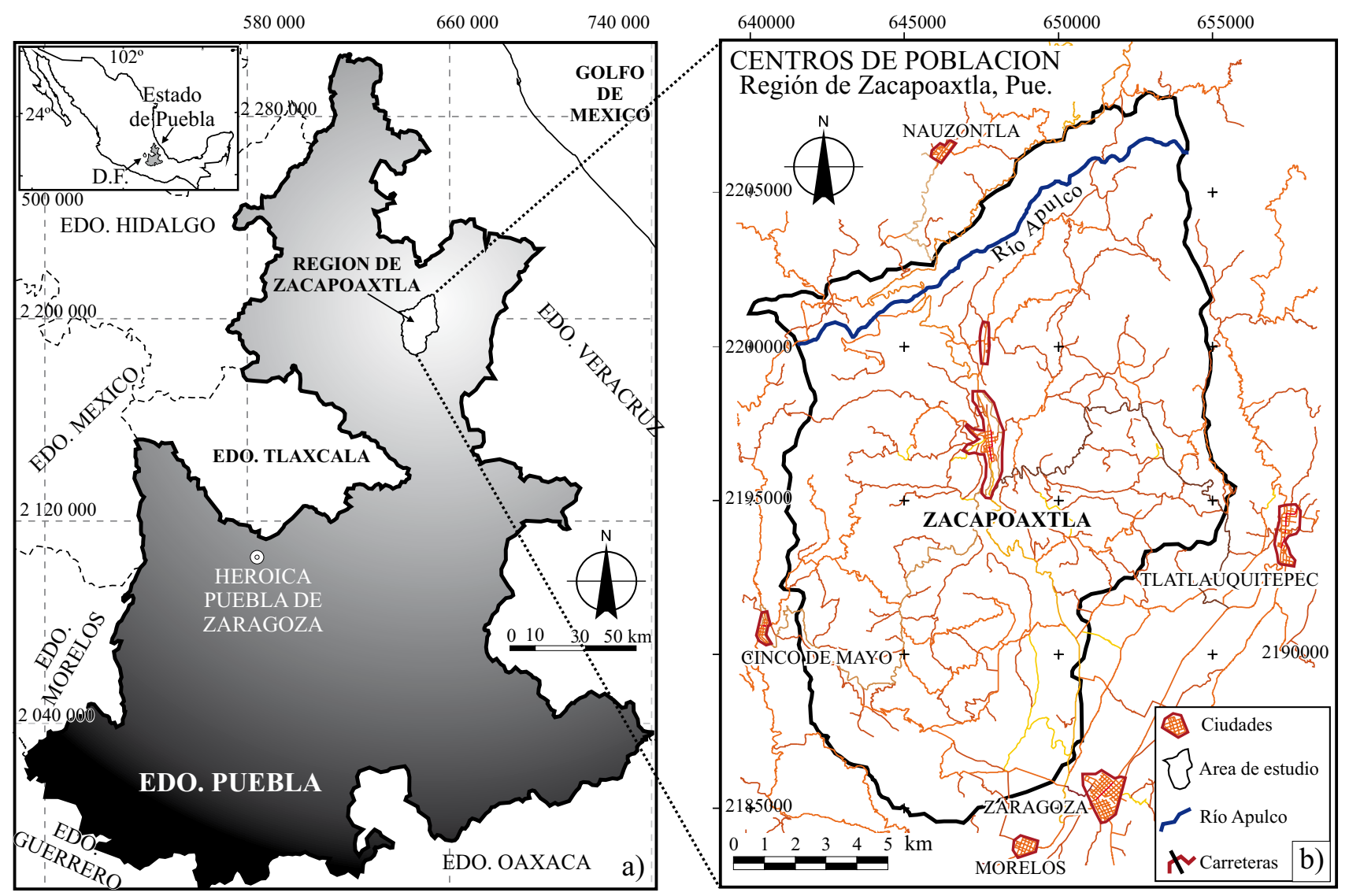

Figura 1. (a) Ubicación de la RdZ, (b) principales centros de población y vías de comunicación en la RdZ.

geotérmicas asociadas, en este caso dejando de lado la litología del Mesozoico. Documento cartográfico importante, lo constituye un mapa geológico regional presentado por Ángeles y Sánchez (2002), para la descripción geológica y geoquímica del Macizo de Teziutlán.

\subsection{Materiales y Método}

El presente trabajo se realizó en cuatro etapas. La primera consistió en una interpretación de fotografías aéreas de la región de estudio a escala 1/75,000 y 1/50,000 (vuelos 1979 y 1995 respectivamente, realizados por el INEGI, 1975, 1995), identificándose fracturamientos principales, unidades litológicas aflorantes y procesos de remoción en masa. En la segunda etapa se realizó la verificación de la información fotointerpretada, muestreo de las unidades sedimentarias y de los depósitos piroclásticos. La tercera etapa radicó en la transferencia de la información al formato digital, mediante un sistema de información geográfica y aplicando la técnica de "digitalización a ojo", que consiste en la comparación de detalles morfológicos foto interpretados con aquellos reconocibles en la cartografía topográfica. Finalmente, en la cuarta etapa se realizaron análisis geoquímicos de fluorescencia de R-X en el Departamento de Geoquímica del Instituto de Geología de la UNAM, utilizando cuatro muestras colectadas del depósito piroclástico de la RdZ.

\section{Geomorfología}

\subsection{Análisis geomorfológico}

Dentro de los elementos morfoestructurales (Figura 2), la RdZ se localiza al NE del CVTM en una zona de transición entre este último y la Subprovincia Carso Huasteco, la cual es considerada como la región más meridional de la Provincia de la SMO (Lugo-Hubp, 1999). El relieve de la RdZ, resulta de la combinación de sierras y altiplanicies intersecadas por valles y profundos barrancos, producto de una erosión asociada a un clima de abundantes precipitaciones, que generan escurrimientos superficiales y ríos jóvenes que desembocan en el Golfo de México. El análisis geomorfológico de la RdZ, muestra que las geoformas más antiguas corresponden a pequeñas sierras erosionadas, compuestas de terrígenos y calizas plegadas e intrusionadas por cuerpos de granito, pertenecientes a la SMO, y que conforman con altitudes de entre 1,600 m y 2,400 m, las sierras: Cinco de Mayo, Las Lomas, Atacpan, y Tlatlauquitepec; todas ellas con orientación N-S, ellas 


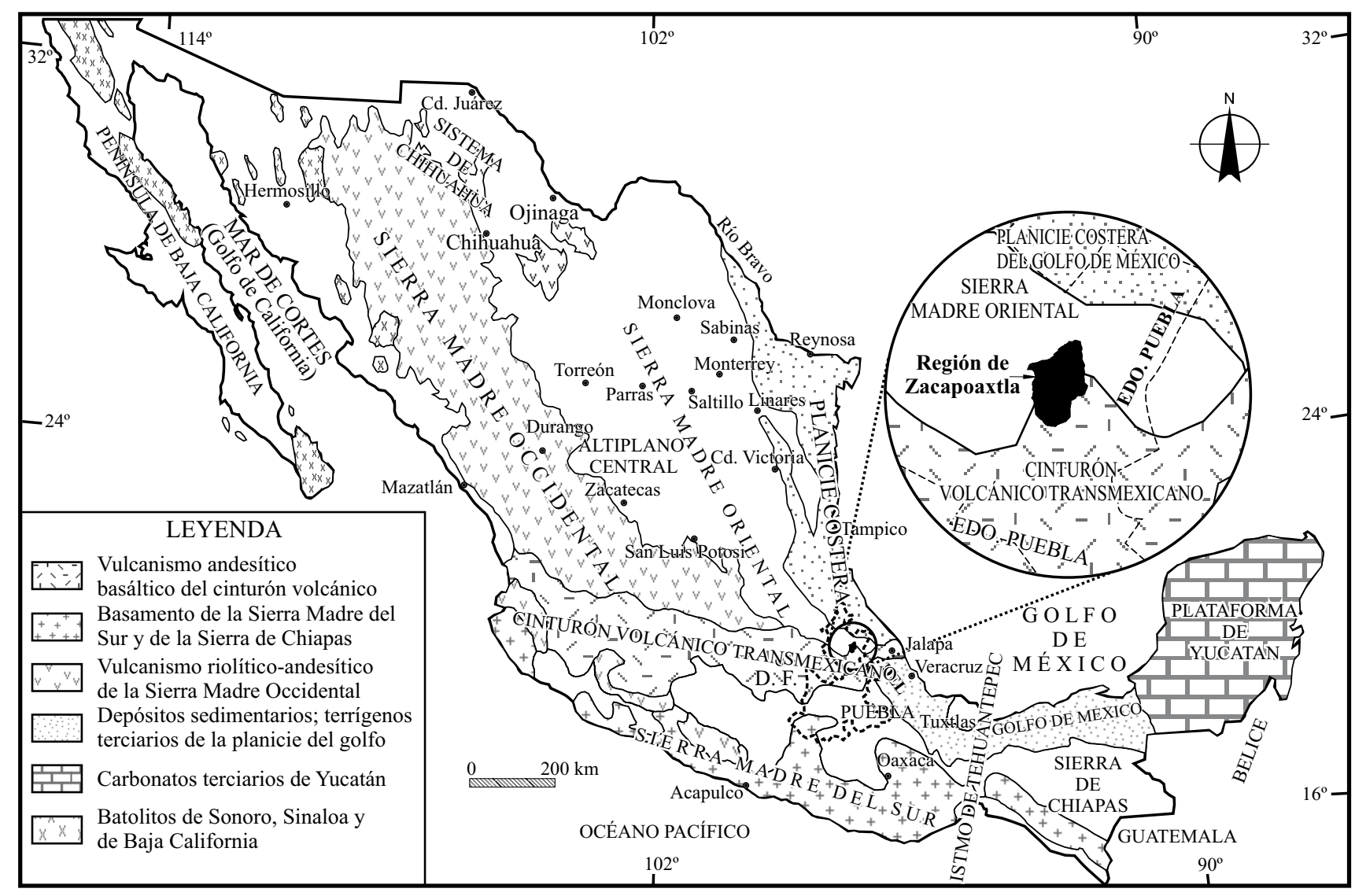

Figura 2. Localización de la RdZ dentro de los elementos morfoestructurales (modificado de Morales y Garduño-Monroy, 1984).

están interrumpidas al norte por la sierra Apulco de misma composición pero con orientación SE-NO y altitudes de entre $1,900 \mathrm{~m}$ y $1,500 \mathrm{~m}$ (Figura 3 ).

La morfología de la SMO contrasta con las formas volcánicas jóvenes representadas en la RdZ, principalmente por la altiplanicie de Zacapoaxtla al centro de la región (Figura 3), constituida por depósitos de flujos piroclásticos de hasta $100 \mathrm{~m}$ de espesor, asociados a una de las etapas eruptivas del centro volcánico Los Húmeros localizado al sureste del área de estudio.

\subsection{Hidrografía}

La RdZ constituye una de las subcuencas del río Apulco, el cual la atraviesa por la parte norte siguiendo la dirección de la sierra Apulco, con un movimiento de flujo O-E que confluye aguas abajo con el río Necaxa, para dar origen posteriormente al río Tecolutla que desemboca finalmente en el Golfo de México. La red fluvial en la RdZ, es en su mayoría de tipo dendrítica (Figura 3), compuesta por los afluentes principales: río Chichilaco (cuarto orden, aplicando el sistema Strahler, 1957), río Tepetitlán (sexto orden) y río Ahuacatlán (cuarto orden), todo ellos con dirección de flujo S-N desembocan en el Río Apulco. La red de avenamiento compuesta por elementos de flujo intermitente y perenne, refleja fielmente los comportamientos estructurales N-S y NE-SO de la RdZ, concordantes con las orientaciones del grupo de sierras que la integran.

La precipitación media anual en la RdZ es de $600 \mathrm{~mm} /$ año en la zona $\mathrm{SO}, 1,250 \mathrm{~mm} /$ año en la zona centro (ciudad de Zacapoaxtla), y en la zona NE alcanza valores de mas de $4,000 \mathrm{~mm} /$ año, así, la RdZ constituye una zona de transición pluvial con valores de lluvia bajos hacia el SO y altos en el NE (Hernández-Madrigal, 2005).

\section{Geologia}

\subsection{Geología regional}

La columna litológica general de la RdZ, se compone a partir de la base, por cuarcitas y limolitas del Jurásico Temprano hasta terrígenos del Cretácico Tardío-Terciario, coronados en su mayoría por depósitos de lavas y flujos piroclásticos relativos a la formación y actividad ígnea del CVTM, que tuvo su máxima expresión en esta zona en el CVLH durante el Terciario Tardío (Plioceno) y Cuaternario. Así, la columna litológica general (Figura 4), es descrita a continuación de la base a la cima: 


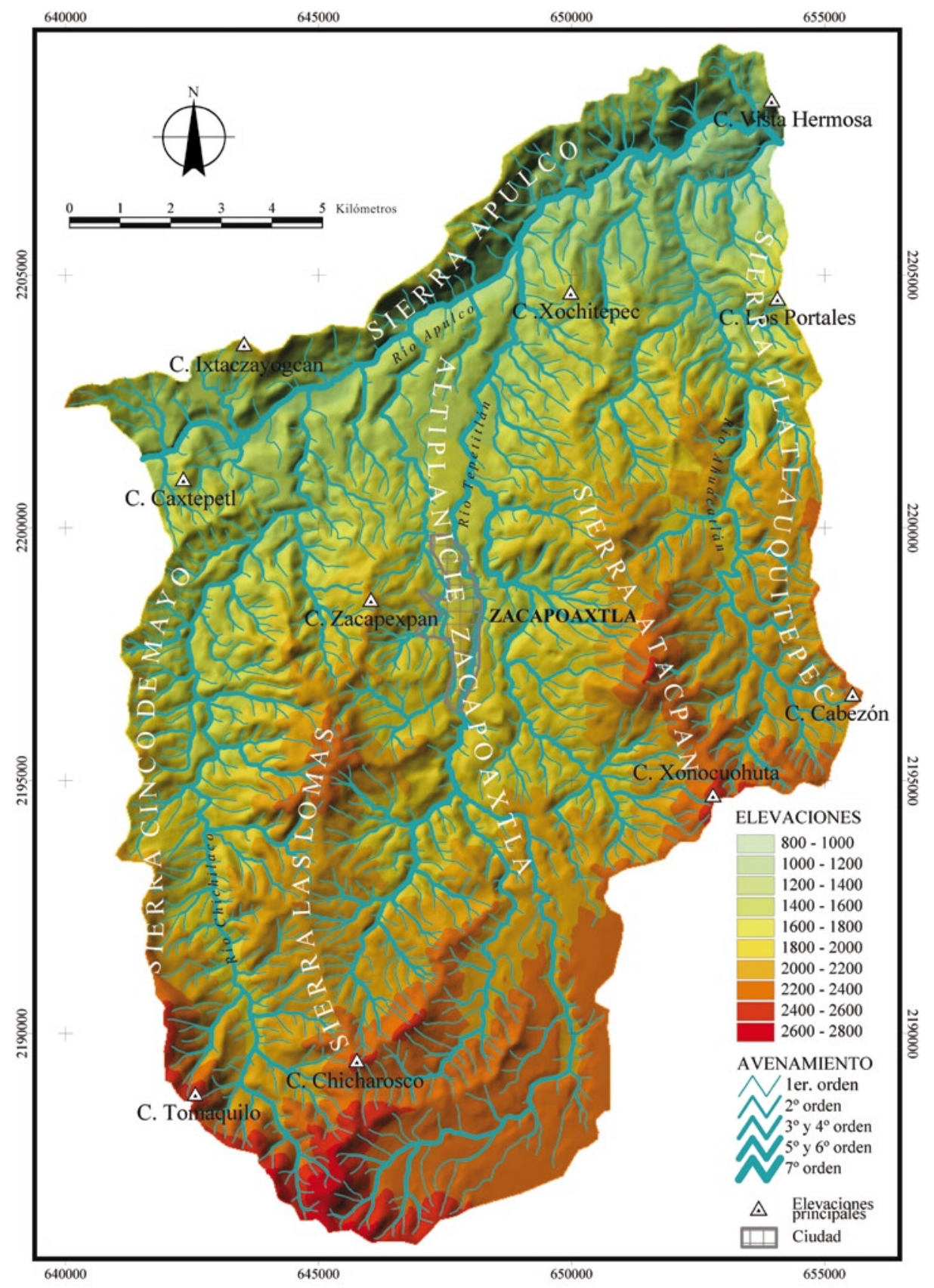

Figura 3. Sierras y avenamiento de la región de Zacapoaxtla.

\section{A. Cuerpos Intrusivos (Gr).}

Reportados por Campos-Enriquez y Garduño-Monroy (1987) como granitos y granodioritas del Mesozoico. Estos autores, con base en estudios geocronométricos de muestras de granodiorita con biotita y hornblenda pertenecientes a la base del complejo, reportan edades de $246 \pm 7$ M.a. (Permiano tardío) y de $181 \pm 5$ M.a. (Triásico tardío y Jurásico temprano). Los afloramientos en la RdZ se presentan principalmente al oeste de la ciudad de Zacapoaxtla en los cerros El Tomaquilo y Ahuatepec, y en los poblados El Progreso, Ahuacatlán y Tepehican (Figuras 3, 4 y 5). Los cuerpos graníticos en estos sitios son de matriz amarilla con tonalidades rojizas y textura fanerítica (Figura 6); completamente intemperizados al menos en superficie.

\section{B. Jurásico Medio (Jmc).}

Se encuentra integrado por las formaciones Tenexcate y Cahuasas. En la zona de estudio por su competencia, ocupa las partes altas de los anticlinales recostados al poniente de Zacapoaxtla. Después de recorrer varias secciones en toda la zona, encontramos que estas litologías se componen de una alternancia de cuarcitas y limolitas con eventuales estratos y hasta bancos de rocas piroclásticas. También se observan en su parte media, capas de conglomerados 


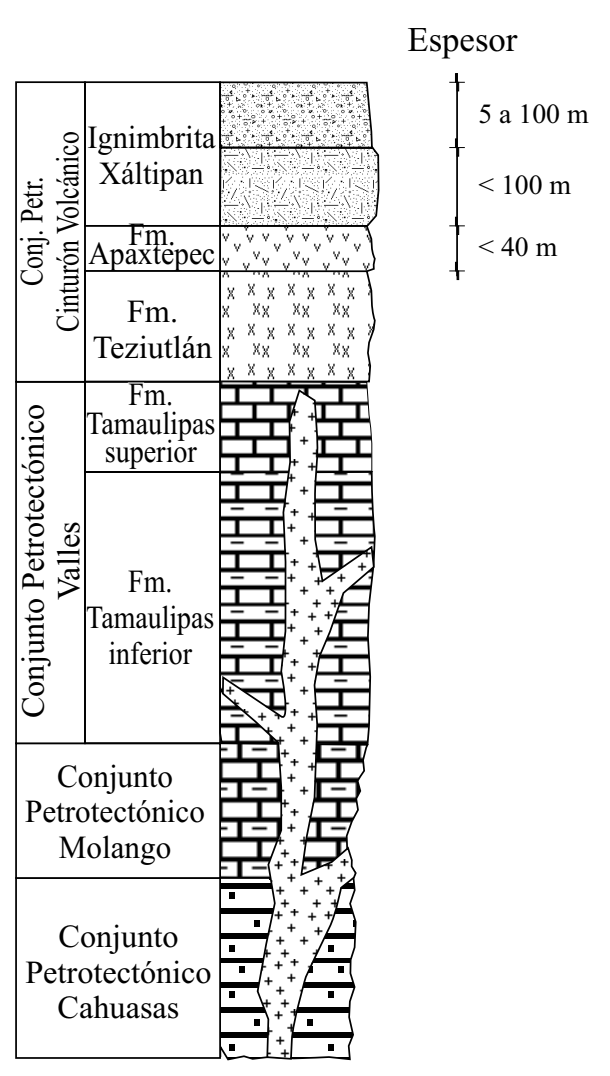

\section{Descripción}

Ix-A Ignimbrita y toba de caída libre de composición riolítica, poco soldadas

Ix-B Ignimbrita Xáltipan de composición riolítica fuertemente soldada

Ap Derrames basálticos en alternancia con brechas volcánicas de color rojizo

Tz Derrames andesíticos y lavas ferrobásicas, intercaladas con tobas y aglomerados

Gr Cuerpos intrusivos compuestos por granitos y granodioritas

Kv Calizas poco arcillosas con colores que varían del gris claro a crema, y de textura bastante fina

Jm Secuencias de calizas y lutitas negras coronadas por macrofauna arrecifal

Jmc Cuarcitas y limolitas con intercalaciones esporádicas de brechas color rojizo

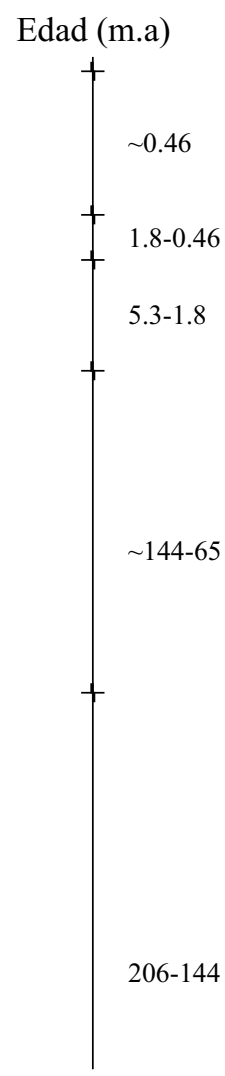

Figura 4. Columna litológica general de la región de Zacapoaxtla.

que se alternan nuevamente con cuarcitas y limolitas de color verdoso y ocre. Existen también intercalaciones esporádicas de brechas color rojo que contienen fragmentos angulares de rocas volcánicas y de limolitas rojas. En la parte intermedia se observan niveles carbonosos con abundantes estrías que evidencian movimientos capa a capa. Rueda (1975) basado en polimorfos le asigna una edad de Toarciense-Bathoniense. Este grupo representa una regresión efectuada durante el Jurásico Medio, que provocó el depósito de sedimentos de origen continental, ya que estos últimos se encuentran sobreyaciendo a calizas oscuras y arcillosas del Jurásico Tardío. Hacia la cima, esta unidad pasa transicionalmente a calizas arcillosas del Jurásico Tardío (basados en Tintinidos) (Figura 5).

\section{Jurásico Tardio (Jm)}

Se compone por depósitos de sedimentos marinos, representados por las formaciones Tepexi, Tamán, San Andrés, Pimienta y Santiago. Las unidades litológicas que lo integran son secuencias de calizas grises de edad Calloviano-Batoniano (Fm. Tepexi), secuencias de calizas y lutitas negras del Oxfordiano coronadas por calizas arcillosas con amonites y macrofauna arrecifal (Fm. Tamán), calizas estratificadas de color gris oscuro de edad Titoniana cubiertas por calizas y dolomías con bandas de pedernal negro (Fm. Pimienta). En esta última formación, Morales y Garduño-Monroy (1984) observaron nódulos calcáreos de hasta $70 \mathrm{~cm}$ de diámetro, que contienen amonitas identificadas del Oxfordiano Tardío-Kimeridgiano. Afloramientos de este conjunto, se observan en la base de la Sierra Las Lomas al oeste de la ciudad de Zacapoaxtla (Figura 4 y 5), presentando una orientación general NNE-SSO.

D. Cretácico (Kv).

Este paquete está conformado por las formaciones Tamaulipas superior (Kvs) y Tamaulipas inferior (Kvi), constituidas por calizas menos arcillosas con colores que varían del gris a gris claro, y de textura bastante fina (mudstone) con nódulos de pedernal negro, cuya densidad incrementa hacia la parte superior, y microfósiles planctónicos (orbitolinas) pertenecientes al Cretácico Inferior. Afloramientos de este conjunto se tienen en la cima de la Sierra Atacpan, al sureste de la ciudad de Zacapoaxtla (Figuras 4 y 5), en donde la roca se observa plegada y fracturada.

\section{E. El Vulcanismo del CVTM}

Estos productos volcánicos son el resultado de la subducción de la Placa de Cocos y Rivera por debajo de la Placa de Norteamérica. Su edad va desde el Oligoceno Tardío al Holoceno (Pasquarè, et al., 1991), con una orientación E-O se prolonga desde Veracruz hasta Tepic. La litología de este paquete volcánico en la RdZ, es asociada a la actividad del CVLH, cuya evolución ha sido ampliamente descrita por Ferríz (1985). Está compuesto de la base a la cima: 


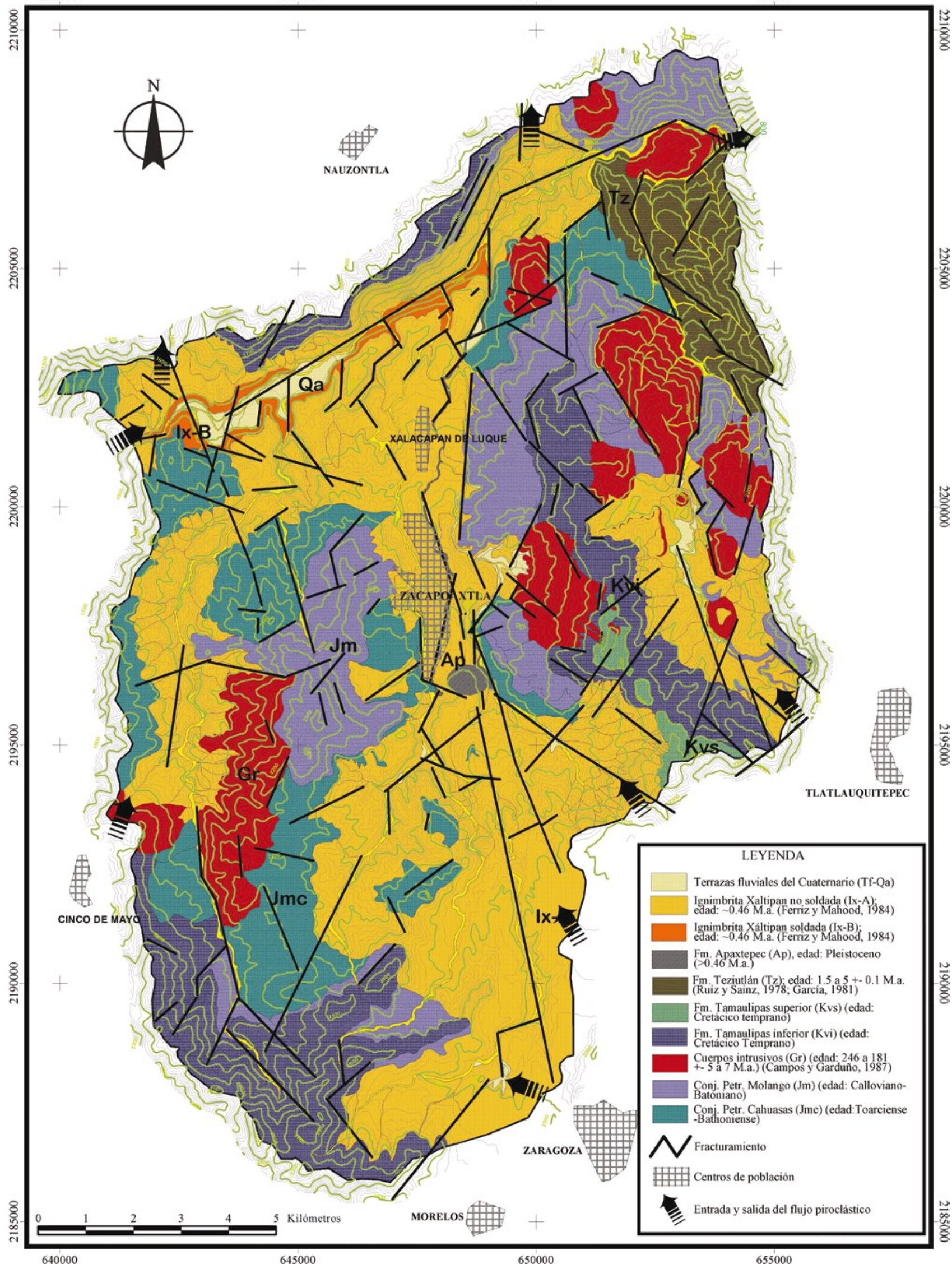

Figura 5. Mapa geológico de la región de Zacapoaxtla. 


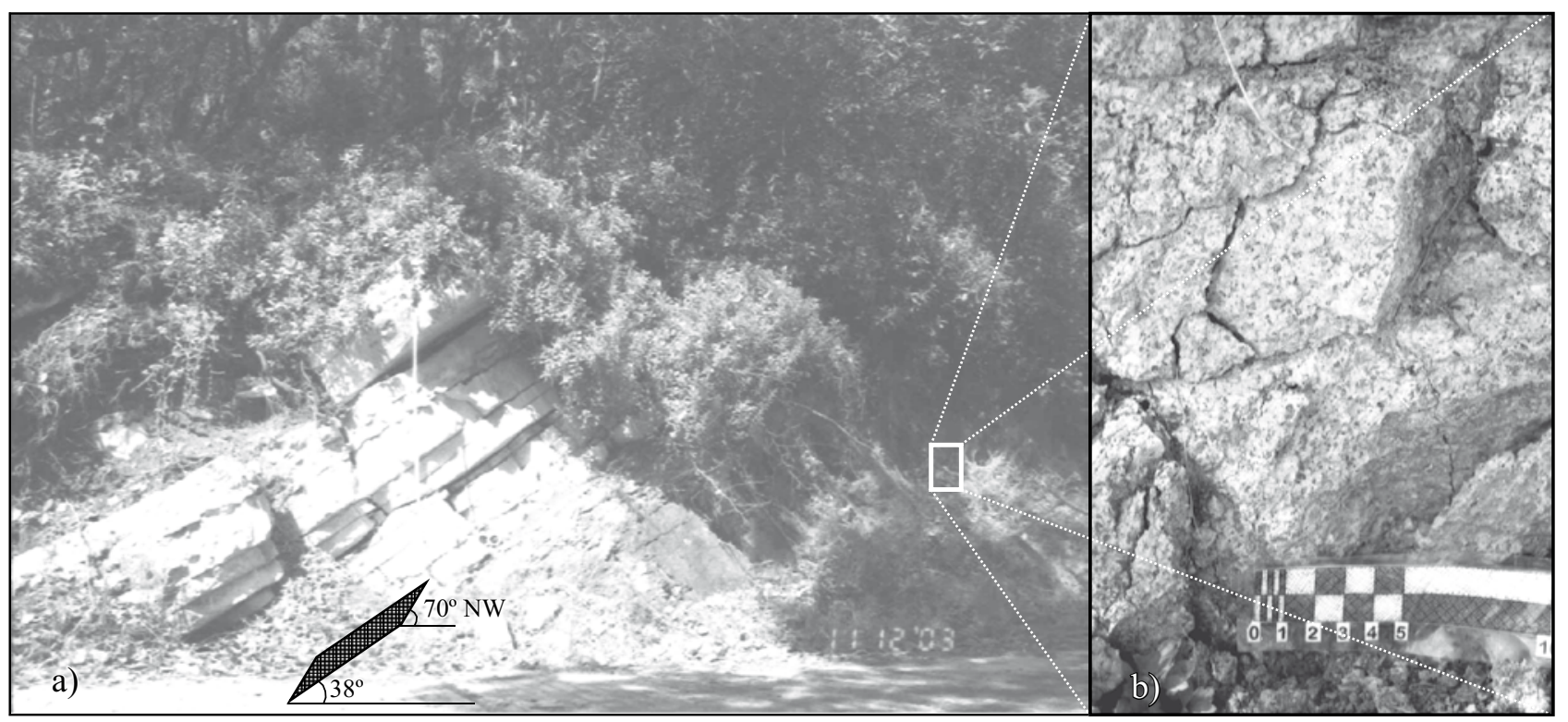

Figura 6. Cuerpos intrusivos en el C. El Tomaquilo (coordenadas UTM, zona 14: $\mathrm{x}=651,715 \mathrm{~m}, \mathrm{y}=2,197,169 \mathrm{~m}$ ) al E de la ciudad de Zacapoaxtla. (a) contacto de intrusivo-sedimentarias metamorfizadas-sedimentaria sana, con planos de contacto inclinados $\left(38^{\circ} \mathrm{SO}\right)$; y (b) muestra de mano de granito intemperizado.

E.1. Fm. Teziutlán (Tz), identificada y descrita por Ángeles y Sánchez (2002) como derrames andesíticos y lavas ferrobasálticas, intercalados con tobas y aglomerados que en conjunto presentan una ligera inclinación al norte, con un espesor máximo que supera los $1,000 \mathrm{~m}$ en los alrededores del CVLH (Ferríz, 1982), y un mínimo de 300 m en los márgenes del río Xucayucan (Ángeles y Sánchez, 2002). Representa una primera actividad volcánica en el CVLH (Ferriz, 1985). Esta formación se identifica como precursora de un período de magmatismo riolítico que inicia con la erupción de lavas que definen la morfología de la periferia del CVLM. Dataciones isotópicas de K-Ar realizadas por Ruiz-Sainz (1978) y Yáñez y García (1982), reportan una edad de 5 y $3.5 \pm 0.3$ a $1.55 \pm 0.1$ M.a. respectivamente. Esta unidad aflora, según el mapa geológico regional presentado por Ángeles y Sánchez (2002), en el NE de la RdZ (Figura 5).

E.2. Fm. Apaxtepec (Ap), es reportada y descrita por Hernández-Madrigal (2005) como un conjunto de coladas de lava basáltica en alternancia con brechas volcánicas de color rojo, formando una unidad de más de $60 \mathrm{~m}$ de espesor, producto de erupciones locales de volcanes monogenéticos (ej. volcán Apaxtepec). Estos depósitos son visibles al NO y E de Zacapoaxtla (Figuras 5 y 7); en el lecho del río Tepetitlán localizado $200 \mathrm{~m}$ al $\mathrm{E}$ del centro histórico de Zacapoaxtla, el afloramiento se extiende hasta el NE de Xilita. La alternancia de litologías provoca una erosión diferencial que se agudiza en las brechas, y que en el río Tepetitlán ha dado forma a numerosas cascadas que van de 3 a más de $10 \mathrm{~m}$ de altura.

A través de un recorrido sobre el río Tepetitlán, a partir del NE y hasta el SE de Zacapoaxtla, se construyó la co- lumna de la Figura 7, compuesta por las unidades que se describen de la base a la cima:

a. Lavas basálticas-andesíticas con espesores de 2 a 30 $\mathrm{m}$, alternando con brechas volcánicas de color rojizo de 1 $\mathrm{m}$ de espesor promedio, toda esta unidad es cubierta por depósitos piroclásticos.

b. Depósito de flujo piroclástico y tobas de caída, que representa en esta zona un cuerpo homogéneo no soldado de más de $90 \mathrm{~m}$ de espesor, es conformado por una arena volcánica $(>80 \%)$, con poco contenido de gravas $(8-12$ $\%)$ y casi sin finos $(<5 \%)$ (Hernández-Madrigal, 2005). Este depósito piroclástico, por su distribución espacial y características físico-químicas que se describirán más adelante, se asoció en este trabajo a la Ignimbrita Xáltipan.

Un kilómetro al sureste del centro histórico de Zacapoaxtla y a escasos $1.5 \mathrm{Km}$ al Sur de Xaltetela, se localiza un volcán monogenético compuesto por cenizas y brechas que Cabrera (1999) llama "volcán Apaxtepec", manifestación principal del vulcanismo de la Fm. Apaxtepec, y que constituye la fuente de los depósitos de lavas al E, NO y NE de Zacapoaxtla. Esta estructura en su parte occidental, se ve cubierta por depósitos de la ignimbrita Xáltipan que en esa zona han formado una mesa de más de $90 \mathrm{~m}$ de espesor y sobre la cual se asienta la ciudad de Zacapoaxtla (Figura 7). Sobre la fundación de la ciudad de Zacapoaxtla, Cabrera (1999) dice “....se tienen datos de que en el año de 1270 d.C., cuando el volcán Apaxtepec hizo erupción sepultó al pueblo de Xaltetelli, dando origen posiblemente a Zacapoaloyan, actualmente Zacapoaxtla...". Dado que la ignimbrita Xáltipan cubre parcialmente a este volcán y a sus productos, estimamos que las edades de estas unidades deben ser mayores a los 460,000 años ( 0.46 


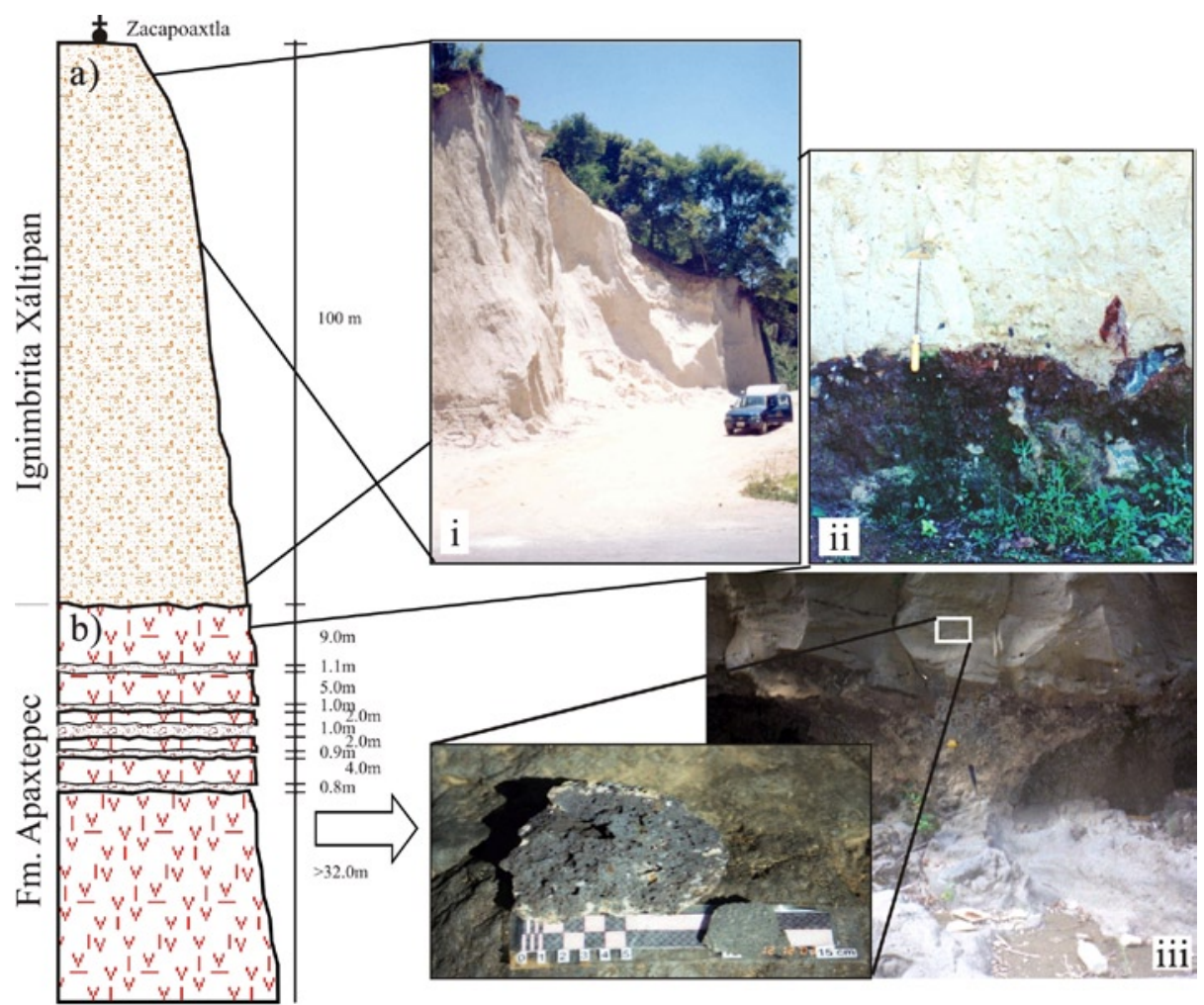

¿v Lavas basálticas $\quad$ Arechas volcánicas

Figura 7. Columna litológica del basamento de la ciudad de Zacapoaxtla. (i) Banco de material de arena volcánica. (ii) Contacto litológico entre la fm. Apaxtepec y el depósito piroclástico. (iii) Fm. Apaxtepec.

M.a.), por lo que se deduce que no existen implicaciones de este evento con la historia prehispánica de Zacapoaxtla, y consecuentemente es necesario reevaluar la hipótesis de su fundación.

E.4. Ignimbrita Xáltipan (Ix) y depósitos de caída. En su mayoría, la pómez en la ignimbrita es afírica y de composición riolítica con alto contenido de sílice que va de 74 a $78 \%$ de $\mathrm{SiO} 2$, a diferencia de la ignimbrita riolítica Zaragoza, tobas Faby y Xoxoctic, cuyo contenido de sílice es entre 64 a $72 \%$ de $\mathrm{SiO} 2$ (Tabla 1). La mayor parte de esta unidad no se encuentra soldada (Ix-A), y en cañones profundos se observa sobreyaciendo a depósitos de ignimbrita fuertemente soldada (Ix-B) de más de $70 \mathrm{~m}$ de espesor. Este arreglo litológico se observa en los márgenes del río Apulco, norte de la RdZ, en donde la ignimbrita soldada pudiera ser confundida con un basalto columnar (Hernández-Madrigal, 2005).

Análisis geoquímicos de fluorescencia de R-X, fueron realizados en el Departamento de Geoquímica del Instituto de Geología de la UNAM, en cuatro muestras colectadas del depósito piroclástico de la RdZ: Xa-01, Xa-02, Xa-12 y Xa-15. Las dos primeras corresponden a la ignimbrita fuertemente soldad del río Apulco, y las otras dos a la ignimbrita no soldada del depósito de Zacapoaxtla. Los resultados de la composición se presentan en elementos mayores y elementos traza, y se comparan con las composiciones obtenidas por Verma y López (1982), Ferríz y Mahood (1984) y Ferriz (1985) (Figura 8). Se observa que la composición de elementos mayores del depósito piroclástico de la RdZ, es concordante con el resto de las muestras de la ignimbrita Xáltipan. También, la ignimbrita soldada del río Apulco presenta mayor contenido de sílice que la no soldada del depósito Zacapoaxtla.

Para la clasificación química del depósito piroclástico de la RdZ, se graficó el contenido de álcalis $(\mathrm{Na} 2 \mathrm{O}+\mathrm{K} 2 \mathrm{O})$ versus contenido de sílice ( $\mathrm{SiO} 2$ ) (Figura 8), siendo clasificadas como ignimbritas riolíticas.

De acuerdo con Ferriz (1985), la ignimbrita Xáltipan y depósitos de caída, son el producto de erupciones de magmas de composición riolítica a andesítica, que representan el fin de la primera fase activa del CVLH. Por otra parte, Ferríz y Mahood (1984) presentan una distribución de las principales unidades piroclásticas asociadas a la actividad volcánica del CVLH, estimando una cobertura de $\sim 3,500$ $\mathrm{km} 2$ para la Ignimbrita Xáltipan, distribuida espacialmente como se muestra en la Figura 9; y estableciendo que la Sierra de Tlaxco (ST), de la cual la RdZ constituye la porción norte, funcionó como barrera que impidió el paso del flujo hacia el noroeste.

Sin embargo en las Figuras 5 y 9, se observa que la 
Ignimbrita Xáltipan supera las barreras de la Sierra de Tlaxco (ST), formando depósitos en la $\mathrm{RdZ}$ que en conjunto suman casi 9,500 ha, lo que representa más del $40 \%$ de la superficie de estudio, y que son además depósitos no registrados en la bibliografía, particularmente en los trabajos de Ferriz. Considerando que los depósitos piroclásticos en la $\mathrm{RdZ}$ presentan un espesor promedio de $60 \mathrm{~m}$, el volumen de la ignimbrita Xáltipan en la $\mathrm{RdZ}$ sería de $5.7 \mathrm{~km} 3$, que sumados a los $230 \mathrm{~km} 3$ reportados por Ferríz y Mahood (1984), darían más de 235.7 km3. Sin embargo, es necesario resaltar que durante la fotointerpretación de litologías en la $\mathrm{RdZ}$, se observaron otros depósitos al NE de la sierra Apulco, con textura y color similar a los depósitos piroclásticos de la $\mathrm{RdZ}$, por lo que el volumen de esta unidad podría verse incrementado con nuevos estudios geológicos al NE de la RdZ.

Según la distribución de las principales unidades piroclásticas provenientes del CVLH, dadas por Ferríz y Mahood (1984), la ignimbrita Xáltipan es el único flujo proveniente de este centro volcánico con emplazamientos en la $\mathrm{RdZ}$, reafirmando así la consideración de que los depósitos piroclásticos de la $\mathrm{RdZ}$ pertenecen a la ignimbrita Xáltipan.

\subsection{Tectónica regional}

La Sierra Madre Oriental en México, que representa uno de los rasgos tectónicos más espectaculares, tiene una dirección general de NO-SE, con variaciones cuando la morfología de su basamento le hace modificar su trayectoria de deformación. Esta última geometría ha generado el corrimiento regional de Parras en el norte de México o bien en la Plataforma de Valles-San Luis (Tardy, 1980). Vista como una continuación de la faja de pliegues y cabalgaduras que llega desde Norteamérica, formada durante el Cretácico superior y Paleoceno (Campa, 1985). El campo de esfuerzos en las estructuras de la SMO fue variable, pero entre Monterrey (N.L.) y Orizaba (Ver.), mantiene una dirección de acortamiento casi ENE-OSO, debido a ello los ejes de las estructuras principales son casi NNO-SSE (Suter, 1980, Eguiluz De Antuñano, et al., 2000).

Es claro que el estilo de deformación de la Sierra Norte de Puebla es de rampas y cabalgaduras, donde eventualmente se involucra el basamento cristalino generando una cuña que ha permitido el desplazamiento y la duplicidad de espesores (Suter, 1980, Eguiluz De Antuñano, et al., 2000).

Tabla 1. Composición de muestras de pómez de las ignimbritas Xáltipan y Zaragoza, y Tobas Faby y Xocotic. (Ferriz y Mahood 1984, y Ferriz, 1985: LH8, LH33, LH42 y LH53. Verma y López, 1982: HF15 y 902. Este trabajo: Xa-01, Xa-02, Xa-12 y Xa-15) (tomado de Hernández-Madrigal, 2005).

\begin{tabular}{|c|c|c|c|c|c|c|c|c|c|}
\hline \multirow{2}{*}{$\begin{array}{l}\text { Unidad } \\
\text { Muestra No: }\end{array}$} & \multicolumn{6}{|c|}{ Ignimbrita riolítica Xáltipan } & \multirow{2}{*}{$\begin{array}{c}\text { Toba } \\
\text { Faby } \\
\text { LH-33 }\end{array}$} & \multirow{2}{*}{$\begin{array}{c}\text { Ignimbrita } \\
\text { riolítica } \\
\text { Zaragoza }\end{array}$} & \multirow{2}{*}{$\begin{array}{c}\begin{array}{c}\text { Toba } \\
\text { Xoxoctic }\end{array} \\
\text { LH-53 }\end{array}$} \\
\hline & LH-8 & HF15 & Xa-01 & Xa-02 & Xa-12 & Xa-15 & & & \\
\hline Latitud N: & $19^{\circ} 41^{\prime} 36^{\prime \prime}$ & $19^{\circ} 42^{\prime} 30^{\prime \prime}$ & $19^{\circ} 54^{\prime} 24^{\prime \prime}$ & $19^{\circ} 54^{\prime} 24^{\prime \prime}$ & $19^{\circ} 51^{\prime} 37^{\prime \prime}$ & $19^{\circ} 54^{\prime} 40^{\prime \prime}$ & $19^{\circ} 39^{\prime} 40^{\prime \prime}$ & $19^{\circ} 40^{\prime} 01^{\prime \prime}$ & $19^{\circ} 41^{\prime} 09^{\prime \prime}$ \\
\hline Longitud O: & $97^{\circ} 15^{\prime} 15^{\prime \prime}$ & $97^{\circ} 16^{\prime} 50^{\prime \prime}$ & $97^{\circ} 37^{\prime} 32^{\prime \prime}$ & $97^{\circ} 37^{\prime} 32^{\prime \prime}$ & $97^{\circ} 35^{\prime} 19^{\prime}$ & $97^{\circ} 35^{\prime} 13^{\prime \prime}$ & $97^{\circ} 19^{\prime} 43^{\prime \prime}$ & $97^{\circ} 24^{\prime} 31^{\prime \prime}$ & $97^{\circ} 24^{\prime} 27^{\prime \prime}$ \\
\hline $\mathrm{SiO}_{2}(\%)$ & 76.6 & 74.08 & 77.88 & 77.15 & 76.71 & 74.03 & 72.20 & 70.10 & 65.10 \\
\hline $\mathrm{TiO}_{2}$ & 0.08 & 0.10 & 0.11 & 0.10 & 0.10 & 0.13 & 0.36 & 0.50 & 0.65 \\
\hline $\mathrm{Al}_{2} \mathrm{O}_{3}$ & 12.9 & 12.80 & 13.03 & 12.78 & 12.97 & 16.67 & 14.80 & 15.20 & 16.50 \\
\hline $\mathrm{Fe}_{2} \mathrm{O}_{3} \mathrm{t}$ & 0.48 & 0.00 & 0.55 & 1.34 & 1.32 & 1.60 & 0.67 & 0.76 & 1.05 \\
\hline $\mathrm{FeO}$ & 0.67 & 1.02 & - & - & - & - & 1.22 & 2.10 & 3.21 \\
\hline $\mathrm{MnO}$ & $<0.02$ & 0.00 & 0.03 & 0.04 & 0.04 & 0.05 & 0.04 & 0.05 & 0.08 \\
\hline $\mathrm{MgO}$ & $<0.10$ & 0.17 & 0.16 & 0.16 & 0.17 & 0.19 & 0.43 & 0.59 & 1.70 \\
\hline $\mathrm{CaO}$ & 0.41 & 0.46 & 0.44 & 0.46 & 0.43 & 0.40 & 1.22 & 1.70 & 3.62 \\
\hline$\otimes a$ & 2.91 & 3.09 & 3.04 & 3.15 & 2.12 & 2.64 & 4.10 & 4.38 & 4.45 \\
\hline $\mathrm{K}_{2} \mathrm{O}$ & 5.8 & 4.92 & 4.75 & 4.81 & 6.13 & 4.29 & 4.88 & 4.48 & 3.44 \\
\hline $\begin{array}{l}\mathrm{P}_{2} \mathrm{O}_{5} \\
\mathrm{ppm}\end{array}$ & $<0.05$ & 0.04 & 0.01 & 0.01 & 0.01 & 0.01 & 0.05 & 0.11 & 0.17 \\
\hline $\mathrm{Rb}$ & 136 & - & 138 & 138 & 168 & - & 127 & 85 & 52 \\
\hline $\mathrm{Sr}$ & 17 & - & 11 & 9 & 9 & - & 108 & 138 & 458 \\
\hline $\mathrm{Ba}$ & 115 & - & 98 & 95 & 93 & - & 780 & 880 & 570 \\
\hline $\mathrm{Y}$ & 31 & - & 35 & 38 & 42 & - & 30 & 30 & 26 \\
\hline $\mathrm{Zr}$ & 104 & - & 175 & 166 & 159 & - & 304 & 326 & 208 \\
\hline $\mathrm{La}$ & 40 & - & - & - & - & - & $<20$ & 34 & 31 \\
\hline $\mathrm{Nb}$ & - & - & 18 & 18 & 19 & - & - & - & - \\
\hline $\mathrm{V}$ & - & - & $<5$ & $<5$ & $<5$ & - & - & - & - \\
\hline $\mathrm{Cr}$ & - & - & $<2$ & $<2$ & $<2$ & - & - & - & - \\
\hline $\mathrm{Co}$ & - & - & $<3$ & $<3$ & 4 & - & - & - & - \\
\hline $\mathrm{Ni}$ & - & - & 3 & 4 & 5 & - & - & - & - \\
\hline $\mathrm{Cu}$ & - & - & 7 & 7 & 11 & - & - & - & - \\
\hline $\mathrm{Zn}$ & - & - & 23 & 35 & 31 & - & - & - & - \\
\hline $\mathrm{Th}$ & - & - & 35 & 36 & 32 & - & - & - & - \\
\hline $\mathrm{Pb}$ & - & - & 17 & 20 & 14 & - & - & - & - \\
\hline
\end{tabular}




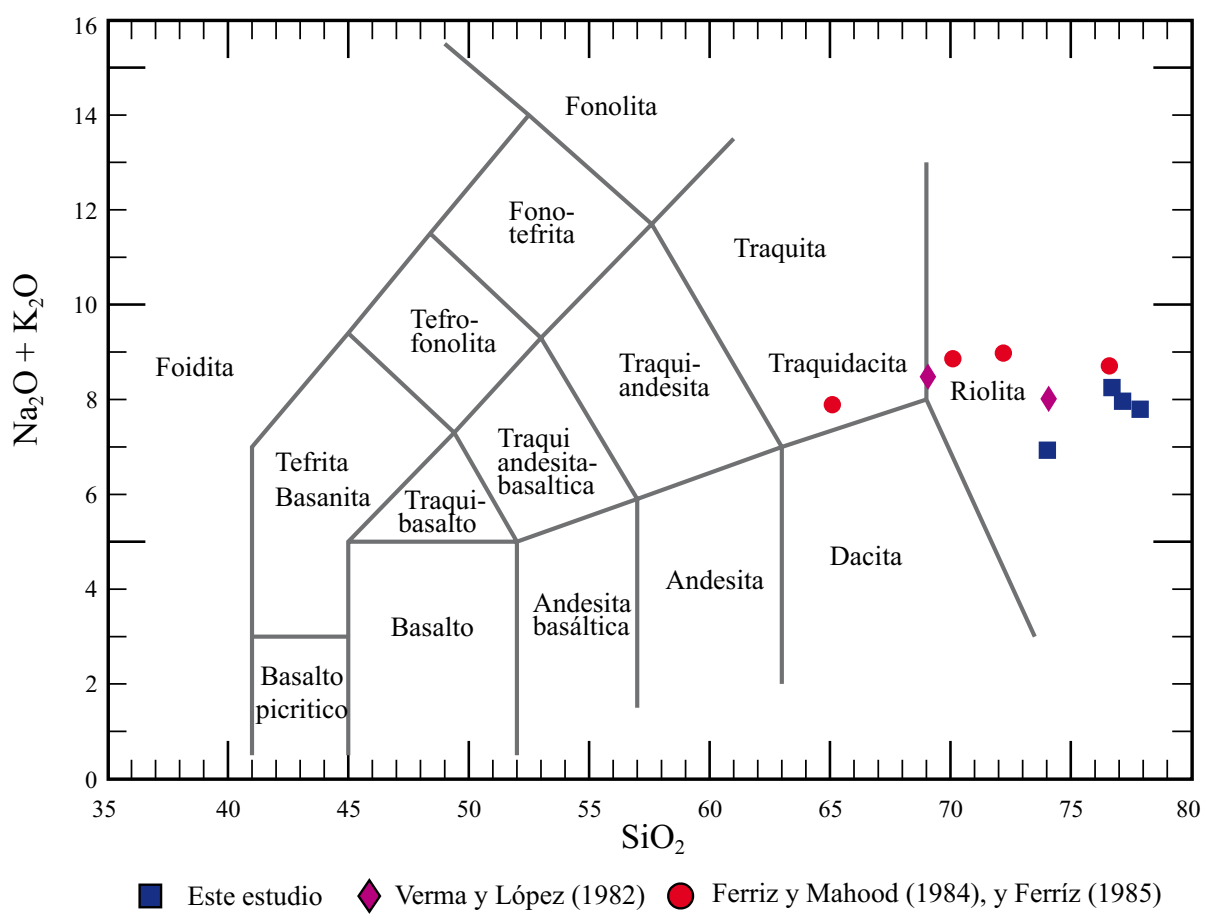

Figura 8. Clasificación química de la ignimbrita Xáltipan, comparando el total de álcalis en relación al contenido de sílice (TAS). Los puntos a cuadros azules corresponden a la ignimbrita muestreada en este estudio; los rombos color magenta son resultados de Verma y López (1982) y los círculos rojos son datos de Ferríz y Mahood (1984), y Ferriz (1985) (tomado de Hernández-Madrigal, 2005).

Los grandes corrimientos de las cuencas mesozoicas sobre las plataformas, han generado también grandes desgarres, el más sobresaliente es el asociado al desbordamiento de Monterrey, se tratan de fallas laterales que de acuerdo al desbordamiento es su sentido (Tardy, 1980, Padilla y Sánchez 1985).

La exploración petrolera ha permitido establecer los estilos de deformación, donde se observan grandes corrimientos de facies de cuencas sobre las plataformas calcáreas (Carrillo, 1961). Tratar de explicar estos corrimientos en la RdZ podría ser azaroso, sin embargo, existen claras evidencias de ello, por ejemplo, los niveles potenciales a generar deslizamientos (capa a capa) son los niveles ricos en carbón del Jurásico Medio, y los niveles incompetentes de arcillas localizados entre bancos competentes (Eguiluz De Antuñano, et al., 2000) (Figura $10,11$ y 12$)$.

En la RdZ, observamos que las facies terrígenas de Cahuasas presentan zonas de despegue (décollement) sobre el basamento granítico, ayudado por las facies arcillosas o bien ricas en carbón, los pliegues son muy amplios y morfológicamente presentan una topografía normal, es decir los anticlinales ocupando las partes altas. Las formaciones calcáreas del Cretácico son más sensibles a la deformación, en ellas se observa una tectónica de pliegues y cabalgaduras donde se destacan grandes desplazamientos horizontales a lo largo de los niveles incompetentes (lutitas o capas muy orgánicas) (Figuras 11 y 12). En forma general y debido a la vergencia del plegamiento y corrimiento, se tienen grandes planos inclinados suavemente en los flancos occidentales de las estructuras, y frentes con elevaciones muy pronunciadas hacia el poniente (Figura 13). Estos estilos de deformación son enmascarados con las rocas graníticas. Sin duda alguna, más del $40 \%$ de acortamiento sugerido por Eguiluz De Antuñano, et al. (2000), en la RdZ fue causado por movimientos capa a capa, más que por la intervención de niveles de yesos, que en la zona son poco frecuentes. En toda el área y sobre todo en una imagen de satélite, Padilla y Sánchez (1985) y, Campos-Enríquez y Garduño-Monroy (1987) aprecian fallas laterales de desgarres de la SMO de dirección general NE-SO, que hacen que algunos frentes sean más espectaculares que otros. El río Apulco en la $\mathrm{RdZ}$ forma parte de estas estructuras, que controlaron la geometría de los desbordamientos de la sierra.

\section{Discusión}

La configuración geométrica y litología de la SMO, el clima, el suelo y los efectos antropogénicos, son los verdaderos motores de la inestabilidad de laderas en la RdZ. Durante las depresiones tropicales 11 a 14 de finales de 1999, el estado de Puebla sufrió uno de los desastres más grandes de su historia (Lugo-Hubp, et al., 2001 y 2005), sin embargo, no todo es debido al clima, nuestro estudio revela que las condiciones geométricas de las deformaciones litológicas juegan un papel relevante en la generación de procesos de remoción en masa (PRM). Por ejemplo, 


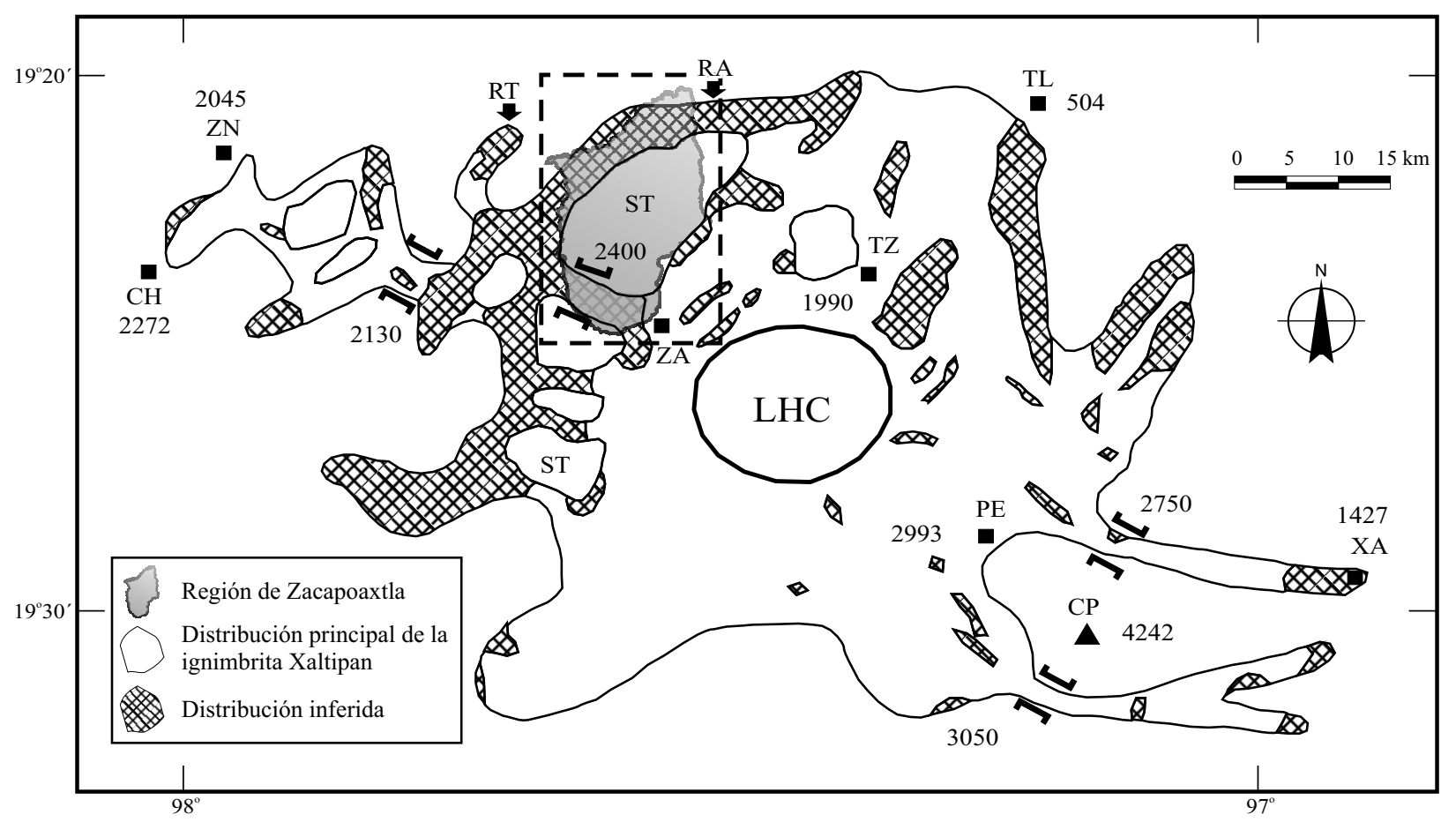

Figura 9.Distribución de la Ignimbrita Xáltipan. LHC: Caldera los Humeros, ZN: Zacatlán, CH: Chignahuapan, ZA: Zaragoza, TZ: Teziutlán, TL: Tlapacoyan, PE: Perote, XA: Xalapa). (CP) Cofre del Perote, (ST) Sierra de Tlaxco, (RA) Río Apulco y (RT) Río Tecuantepec; los corchetes muestran "puertos" por donde el flujo pasó y el número indica la elevación de esos puntos (modificado de Ferríz y Mahood, 1984).

en los estilos propuestos por Eguiluz De Antuñano, et al. (2000) de rampas y cabalgaduras para la RdZ, se presentan dos dinámicas de deformación gravitacional de laderas (Figura 13).

En las rampas, generalmente flancos oeste de las sierras Cinco de Mayo, Las Lomas, Atacpan y Tlatlauquitepec, los PRM de mayor registro consisten de deslizamientos traslacionales de bloques de rocas (Figura 13a), y deslizamientos traslacionales y rotacionales superficiales (menos de $4 \mathrm{~m}$ de profundidad) de suelos y lapilli. En los primeros, los contactos entre rocas y detritos con niveles inferiores ricos en carbón y arcillas del Jurásico, motivan el desarrollo de superficies de debilidad por efecto de un ángulo de fricción bajo y presión de poro alta, particularmente en condiciones saturadas, influenciada además por la inclinación de la ladera asociada a la geometría de la rampa, por lo anterior, la profundidad del deslizamiento depende del espesor de roca que descansa en el estrato débil. En tanto los deslizamientos superficiales, se asocian especialmente a diferencias importantes de conductividad hidráulica entre suelos y lapilli con rocas y paleosuelos que los subyacen, estos últimos forman barreras impermeables que obstaculizan la infiltración del agua, por lo que ésta al acumularse satura la base del material sobreyacente y da paso al desarrollo de superficies de baja resistencia al cortante, es decir, deslizamientos traslacionales que evolucionan a flujos de detritos y lodos conforme se incrementa el contenido de agua en la masa inestable (Figura 13b).

Por el otro lado, en los frentes de corrimiento (flancos orientales de las mismas sierras), y por ende en las grandes elevaciones topográficas compuestas de rocas competentes sobre rocas terrígenas, se observan caídas y volcamientos de bloques de rocas y detritos en escarpes principales de hasta $100 \mathrm{~m}$ de altura, formados por la deformación gravitacional profunda de ladera (DGPL) (Figura 13c), también conocida como "Sackung" o flujo de rocas (Bisci, et al. 1996). En la DGPL, el cuerpo en movimiento puede o no presentar flancos bien definidos con una deformación que está estrechamente ligada a la estructura de la roca (Figuras 13 d, e, f y g). Esta forma de inestabilidad se asocia a una reptación que se localiza a varias decenas de metros de profundidad (Dramis y Sorisso-Valvo, 1994), en respuesta a un esfuerzo desviador que en el centro del cuerpo de la ladera es superado por el confinamiento, por lo que el desplazamiento de la roca en esa zona se desarrolla bajo una deformación plástica lenta y continua (reptación) (Figura $13 \mathrm{~h}$ ). La DGPL resulta particularmente importante desde el punto de vista del análisis de riesgo, debido a que se desplaza con movimientos lentos que repentinamente pueden incrementar su velocidad bajo los efectos sísmicos o de precipitaciones excepcionales, para dar paso a grandes avalanchas de rocas y detritos que pueden sepultar a poblaciones localizas ladera abajo. Las fallas laterales NE-SO que dan origen a la trayectoria del Río Apulco, en el flanco sur de la sierra Apulco, forman este tipo de estructuras y también están asociadas con DGPL.

Por otra parte, los afloramientos de granitos y granodioritas intemperizados son materiales ajenos a la geometría de 


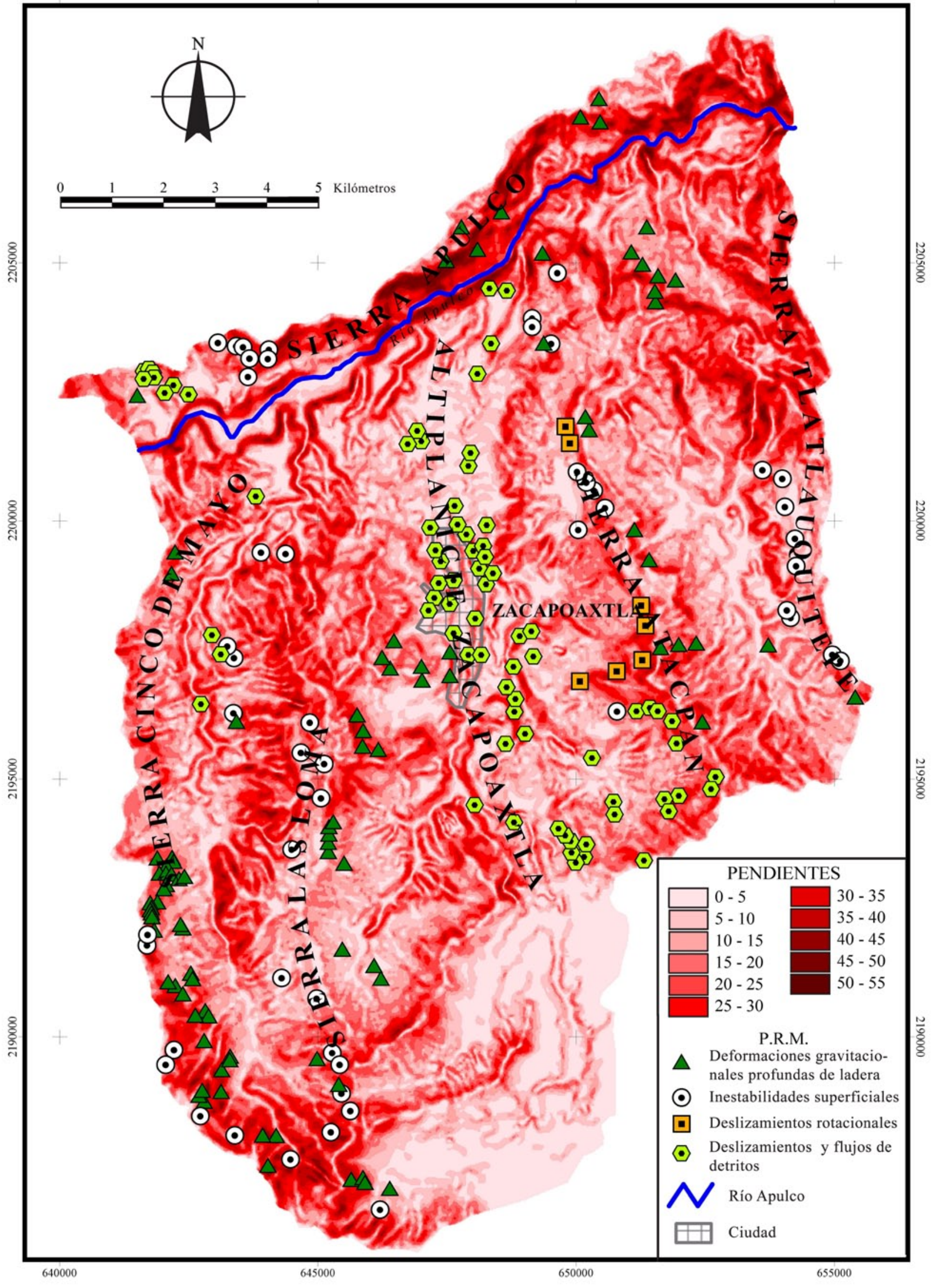

Figura 10. Mapa de pendientes con principales tipos de inestabilidades de ladera (modificado de Hernández-Madrigal, 2005). 

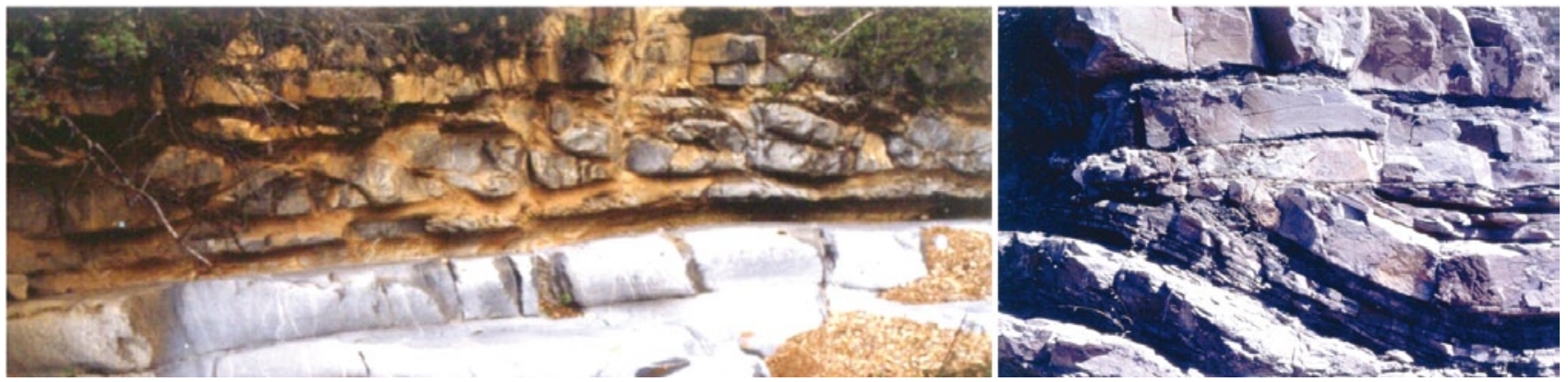

Figura 11. En ambas imágenes se logra observar los movimientos capa a capa de las formaciones del Cretácico. Por encima y debajo de estos planos de corrimiento las unidades parecen estar sin deformación. Los movimientos capa a capa se llevan a cabo en facies de calizas arcillosas o bien en areniscas.

la deformación de la SMO, compuestos principalmente por arcillas y limos de consistencia blanda y poca resistencia al esfuerzo cortante bajo condiciones de saturación, por lo que son más susceptibles a los PRM bajo regimenes de precipitación excepcional. Finalmente, los deslizamientos rotacionales en flancos de depósitos de arenas volcánicas que conforman la ignimbrita Xáltipan no soldada, presentan un mecanismo de detonación totalmente diferente al del resto de las litologías en la RdZ. Estos depósitos piroclásticos, son limitados por laderas muy inclinadas de hasta $80 \mathrm{~m}$ de altura, compuestas por arenas permeables de baja cohesión $(<4 \mathrm{kN} / \mathrm{m} 2)$ y ángulo de fricción alto $\left(42^{\circ}\right)$ en condiciones no saturadas (Hernández-Madrigal, 2005). Durante eventos excepcionales de precipitación, el contenido de agua en la base del depósito piroclástico no soldado se incrementa rápidamente debido a una elevada conductividad hidráulica del material $(5.4 \times 10-5 \mathrm{~m} / \mathrm{seg})$ (Hernández-Madrigal, 2005) y el contacto litológico con paleosuelos o macizos rocosos menos permeables, lo que trae como consecuencia un incremento en la presión de poro y por lo tanto un abatimiento en la resistencia al cortante, favoreciendo el desarrollo de deslizamientos rotacionales con falla por el pie del depósito piroclástico durante eventos excepcionales de lluvia.

\section{Conclusiones}

La geología de la Región de Zacapoaxtla es definida por la interacción de los Terrenos Sierra Madre Oriental

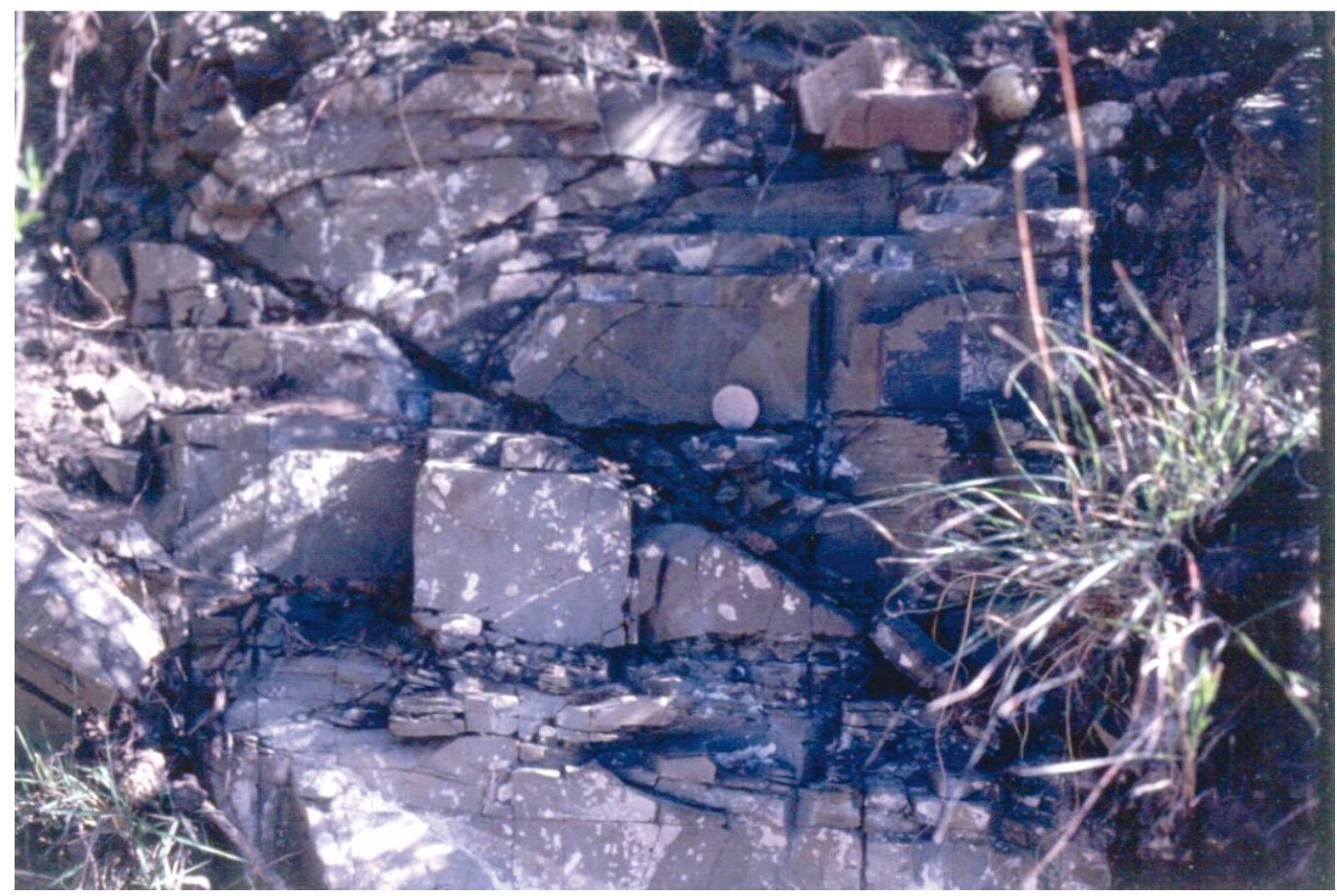

Figura 12. Rampa en facies del Cretácico donde se aprecia poca deformación. 

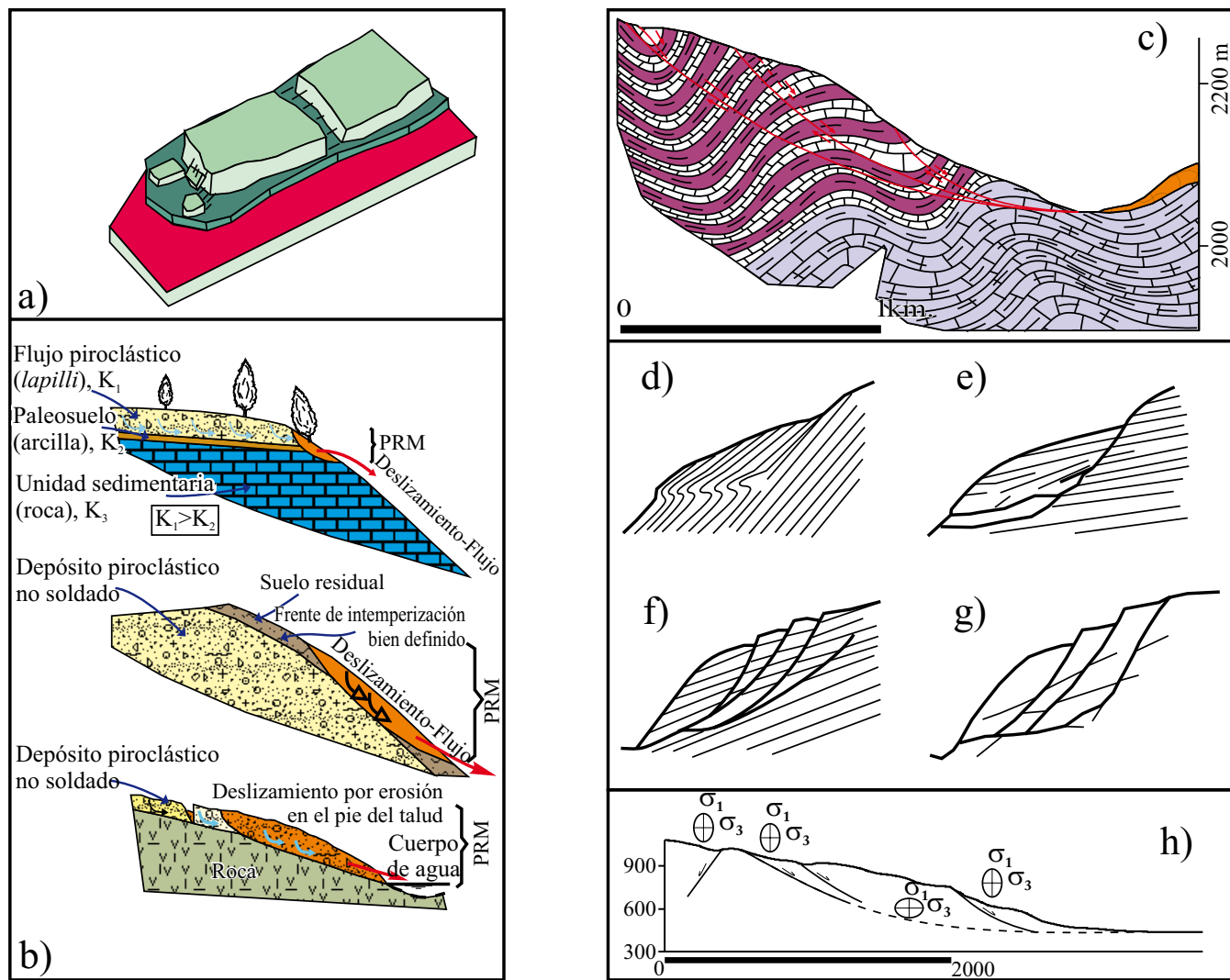

d)

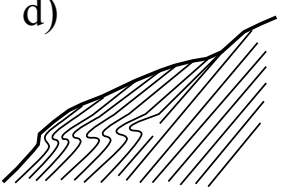

e)

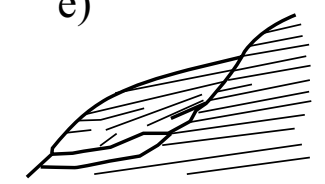

f)

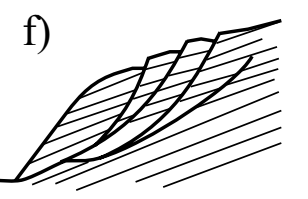

g)
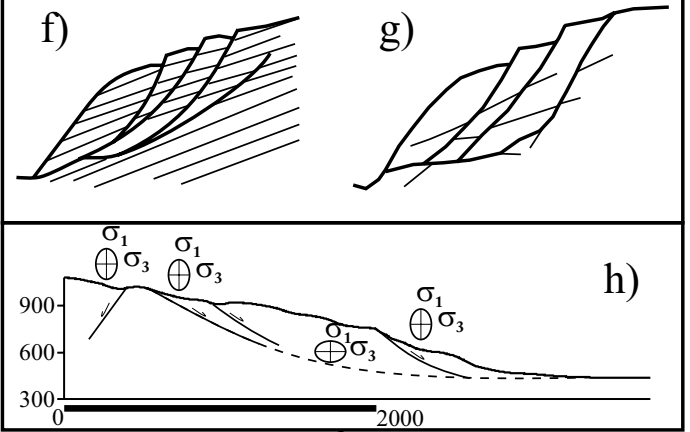

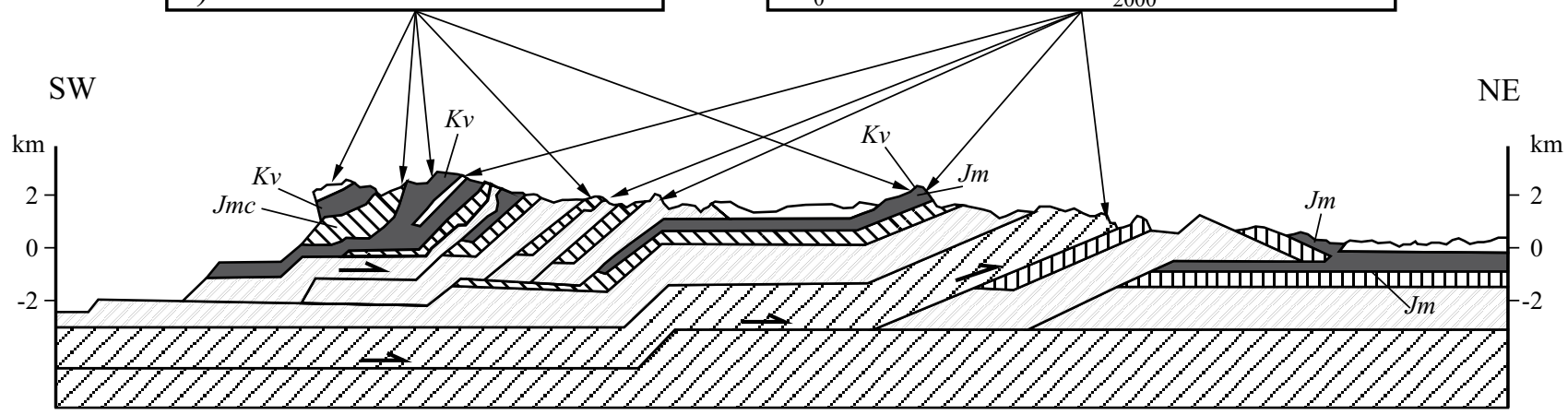

Jmc $=$ arenisca del Jurásico medio (Fms. Tenexcate y Cahuasas); Jm = carbonatos y lutitas del Jurásico Tardío (Fms. Tepexi, Tamán, San Andrés Pimienta y Santiago. $\mathrm{KV}=$ carbonatos del Cretácico Inferior (Fms. Tamaulipas superior e inferior)

Figura 13. Características geométricas fault-bend fold en la Sierra de Zacapoaxtla (modificado de Eguiluz De Antuñano, et al., 2000); con tipos de inestabilidades de laderas asociados: (a) deslizamientos traslacionales de bloques de rocas, (b) deslizamientos rotacionales superficiales con flujos de detritos, (c) deformación gravitacional profunda de ladera. (d), (e), (f) y (g), tipos de deformaciones gravitacionales profundas de ladera, (h) arreglo de esfuerzos desviadores en las deformaciones gravitaciones profundas.

y Cinturón Volcánico Trans Mexicano. Se identifican basaltos intercalados con brechas volcánicas posteriores a la formación Teziutlán, que dan origen a la formación Apaxtepec con afloramientos al E de Zacapoaxtla. Ejemplo de esta formación se encuentra en el volcán Apaxtepec, con edad inferida por el arreglo litológico del entorno, mayor a los 460 mil años, por lo que su actividad no puede ser asociada a la historia prehispánica de la región. Datos químicos y cartográficos demuestran que los depósitos piroclásticos de la región de Zacapoaxtla, pertenecen a la misma ignimbrita Xáltipan, por lo que la distribución de ésta presentada en el mapa geológico de la región de Zacapoaxtla, implica una modificación de su distribución espacial dada por Ferríz y Mahood (1984). Finalmente, la dinámica de procesos de remoción en masa en el área de estudio, responde a tres factores determinantes principales: la geometría de la deformación en las unidades de la Sierra Madre Oriental; propiedades mecánicas en los materiales arcillosos y limosos de cuerpos intrusivos intemperizados, paleosuelos y suelos residuales; y condiciones hidráulicas, mecánicas y geométricas en los depósitos de la ignimbrita Xáltipan no soldada. 


\section{Agradecimientos}

Se agradece la colaboración de las autoridades municipales de Zacapoaxtla y Protección Civil del estado de Puebla, así como los apoyos otorgados por el CONACYT a través del proyecto J33428-T, y al Programa de Becas para estudios de Posgrado de la DGEP de la UNAM. Se agradece especialmente el apoyo técnico de los Profs. Giovanni B. Crosta y Nicoleta Fussi, y Dott. Elena Valbuzzi.

\section{Referencias Bibliográficas}

Ángeles, M. E. y Sánchez, M. S., 2002. "Geología, geoquímica y geología estructural de las rocas del basamento del macizo de Teziutlán, Estado de Puebla". Facultad de Ingeniería; Universidad Nacional Autónoma de México. Tesis de licenciatura para el título de Ingeniero Geólogo. 105 p.

Bisci, C., Drams, F. y Sorriso-Valvo, M., 1996."Rock flow (Sackung)". En Landslide Recognition, editado por: Dikau, R., Brunsden, D., Schortt, L., e Ibsen, M. L. John Wiley \& Sons, pp. 150-160.

Cabrera, M. J., 1999. "Zacapoaxtla, la ciudad del 25 de abril". Secretaría de Cultura, Puebla. 85 p.

Campa, M. F., 1985. "The mexican thrust belt”. In Howell, D.G., ed., Tectonostratigraphic terranes of Circum-Pacific region: CircumPacific Concil for Energy Mineral Resources, Earth Science Series, v. 1, p. p. 299-313.

Campos-Enríquez, J. O. y Garduño-Monroy, V. H., 1987. "The Shallow structure of Los Humeros and Las Derrumbadas geothermal fields, México". Geothermics, Vol. 16, No. 5/6. p.p. 539-554.

Carrasco, B., 1997. "Albian Sedimentation of Submarine Autochthonous and Allochthonous Carbonates. East adge of the Valles- San Luis Potosi, Platform, Mexico". SEPM Special Publication, $\mathrm{N}^{\circ} 25$, p.p. 263-275.

Carrillo, B. J., 1961. "Geología del Anticlinorio Huizachal Peregrina al noroeste de Ciudad Victoria, Tamps: Boletín de la Asociación Mexicana de Geólogos Petroleros, v. 13, pp. 1-98.

De la Cruz-Martínez, V., 1983. "Estudio geológico a detalle de la zona geotérmica Los Humeros, Puebla”. Comisión Federal de Electricidad. Gerencia de Proyectos Geotermoeléctricos. Departamento de Exploración. Informe 10/83. 52 p.

Dramis, F., y Sorisso-Valvo, M., 1994. "Deep-seated gravitational slope deformations related landslides, and tectonics". Eng. Geology, 38, pp. 231-243.

Eguiluz De Antuñano, Samuel, Aranda, G.M, y Marrett, R., 2000. "Tectónica de la Sierra Madre Oriental, México". Boletín de la Sociedad Geológica Mexicana. V. LIII, pp. 1-26.

Ferriz, H., 1982. "Geologic and preliminary reservoir data on the Los Humeros geothermal system, Puebla, México". In Proceedings Eight Workshop Geothermal Reservoir Engineering. Standford University, Standfor, California, p. p. 19-24.

Ferríz, H., 1985. "Zoneamiento composicional y mineralógico en los productos eruptivos del centro volcánico de los Humeros, Puebla, México". Geof. Int. Vol. 24-1, p.p. 97-157.

Ferríz, H. y Mahood G.A., 1984. "Eruption rates and compositional trends at Los Humeros Volcanic Center, Puebla, Mexico". Journal of Geophysical Research 89, p.p. 8511-8524.

Hernández-Madrigal, V. M., 2005. "Caracterización de los procesos de remoción en masa en la Región de Zacapoaxtla, Sierra Norte de Puebla, México". Facultad de Filosofía y Letras. Universidad Nacional Autónoma de México. Tesis de posgrado para obtener el grado de Doctor en Geografía. 120 p.
Instituto Nacional de Estadística, Geografía e Informática (INEGI), 1979. Fotografías aéreas, escala 1/50 000: México D.F., Secretaria de Programación y Presupuesto, Instituto Nacional de Estadística, Geografía e Informática.

Instituto Nacional de Estadística, Geografía e Informática (INEGI), 1995. Fotografías aéreas, escala 1/75 000: México D.F., Secretaria de Programación y Presupuesto, Instituto Nacional de Estadística, Geografía e Informática.

Lugo-Hubp, 1999. "El relieve de la Republica Mexicana". Universidad Nacional Autónoma de México. Instituto de Geología. Revista, vol. 9, num. 1, p. p. 82-111.

Lugo-Hubp, J., Vázquez, C. T., Melgarejo, P. G., García J. F. y Matias R. G., 2001. "Procesos gravitacionales en las montañas de Puebla". Ciencia y Desarrollo, v. XXVII, no. 157, p. p. 25-33.

Lugo-Hubp, J., Zamorano-Orozco, J. J., Capra, L., Inbar, M. y AlcántaraAyala, I., 2005. "Los procesos de remoción en masa en la Sierra Norte de Puebla, octubre de 1999: Causas y efectos". Revista Mexicana de Ciencias Geológicas, v. 22, núm. 2, pp. 212-228.

Martínez-Serrano, R. G., 2000. "Chemical variations in hydrothermal minerals of the Los Humeros geothermal system, Mexico". Geothermics 31, p. p. 579-612.

Morales, J. y Garduño-Monroy, V. H., 1984. "Prospecto Huachinango, Informe geológico Final“. Proyecto C-4001. PEMEX (Inédito). $147 \mathrm{p}$.

Padilla y Sánchez, R., 1985. "Las estructuras de la curvatura de Monterrey, Estados de Coahuila, Nuevo León, Zacatecas y San Luis Potosí". Universidad Nacional Autónoma de México. Instituto de Geología, Revista, v. 6, pp. 1-20.

Pasquarè, G., Ferrari L., Garduño, V. H., Tibaldi, A. y Vezzoli, L., 1991. "Geology of the central sector of Mexican Volcanic Belt, States of Guanajuato and Michoacan". Geol. Soc. Am. Map and Chart series, $22 \mathrm{p}$.

Rueda, G. J., 1975. "El estudio de los Constituyentes Orgánicos e Inorgánicos de las Formaciones Huayacocotla (Liásico) y Rosario (Jurásico Medio) del E de México y su Relación con la Tectónica, Generación y Entrampamiento de Hidrocarburos". Proyecto 3019. IMP. (Inédito).

Ruiz-Sainz, P., 1978. "Estudio radiométrico de las rocas ígneas y metamórficas del área Villa Juárez-Tlapacoyan, Estado de Veracruz”. Inst. Méx. Petróleo. Proyecto C. 1007, p. p. 1-28.

Strahler, A., N., 1957. "Quantitative analysis of watershed geomorphology". Trans. Am. Geophys. Union, 38. Pp. 913-920.

Suter, M., 1980. "Tectonics of the external part of the Sierra Madre Oriental foreland. Thrust. -and- fold belt between Xilitla and Moctezuma river (Hidalgo and San Luis Potosí states)". México, D. F., Universidad Nacional Autónoma de México, Instituto de Geología. Revista, v. 4, p. p. 19-31.

Tardy, M., 1980. "Contribution à l'étude géologique de la Sierra Madre orientale du Mexique". Thése Doct. Sci. Univ. P. -et- M. -Curie, Paris, 459 p. (Inédit).

Verma, S. P. y López, M., 1982. "Geochemistry of Los Humeros Caldera, Puebla, México". Bull. Volcanol., Vol. 45-1, p. p. 63-79.

Yañez, G. C. y García, D. S., 1982. "Exploración de la Región Geotérmica Los Humeros- Las Derrumbadas". Estados de Puebla y Veracruz. Comisión Federal de Electricidad. 96 p.

Manuscrito recibido: Octubre 9, 2006

Manuscrito corregido recibido: Enero 26, 2007

Manuscrito aceptado: Febrero 20, 2007 